\title{
Air-sea exchange in the Black Sea estimated from atmospheric analysis for the period 1979-1993
}

\author{
Corinna Schrum $^{\mathrm{a}, *}$, Joana Staneva $^{\mathrm{b}}$, Emil Stanev $^{\mathrm{b}}$, Emin Özsoy $^{\mathrm{c}}$ \\ a Zentrum für Meeres- und Klimaforschung der Universität Hamburg, Institut für Meereskunde, Troplowitzstr. 7, \\ D-22529 Hamburg, Germany \\ ${ }^{\mathrm{b}}$ Department of Meteorology and Geophysics, University of Sofia 5, James Bourchier Street, 1126 Sofia, Bulgaria \\ ${ }^{\mathrm{c}}$ Institute of Marine Sciences, Middle East Technical University, P.K. 28 Erdemli-Icel 33731, Turkey
}

Received 17 January 2000; accepted 2 May 2001

\begin{abstract}
The air-sea exchange in the Black Sea is revisited in the paper on the base of data provided from the ECMWF atmospheric re-analysis for the period 1979-1993. Climatological characteristics of analysis data are compared against available climatic data, demonstrating quite a good consistency. Several drawbacks are found: too low temperatures in the easternmost part of the sea, too low dew point temperature and slight underestimation of precipitation. However, the seasonal and inter-annual oscillations are resolved correctly, as well as the horizontal patterns of air-sea exchange. The shallow penetration of thermal signal in the Black Sea is well detected by the very small heat transports inferred from the ECMWF data. Thus, the conclusion is that the analysis 'sees' quite well the major thermal peculiarity of the Black Sea associated with its extremely small thermal inertia caused by the specific stratification. (C) 2001 Elsevier Science B.V. All rights reserved.
\end{abstract}

Keywords: Black Sea; Air-sea interaction; Heat flux; Water flux

\section{Introduction}

The reduced air-sea heat exchange in the Black Sea (comparable to the heat exchange in a basin with a depth of $75-100 \mathrm{~m}$ only) is a consequence of the extremely strong stratification. The shallow penetration of the atmospheric seasonal signal is thus a demonstration of the low Black Sea ventilation. Though the air-sea exchange seems to be mostly an

\footnotetext{
* Corresponding author. Tel.: +49-40-428-38-5989; fax: +4940-560-5724.

E-mail address: schrum@dkrz.de (C. Schrum).
}

issue addressed in meteorology (marine meteorology), studies addressing the ventilation of deep water (even from purely oceanographic perspectives) cannot be undertaken ignoring the limited air-sea exchange in the Black Sea. New atmospheric data for the Black Sea region constantly contribute to correcting oceanographic concepts; however, some of the available ones as satellite data (e.g. Korotaev et al., 1998) or the global atmospheric re-analysis data from the European Center of middlefrist weather forecast (ECMWF, Gibson et al., 1996) have not yet been subject to detailed consideration with respect to the heat balance in the area of the Black Sea. This is quite important especially for studies dealing with 
the method of regional ocean and ocean-atmosphere modeling. The increasing interest in climate dynamics, ocean modeling and regional coupled atmosphere-ocean modeling imposes strong requirements for the efficient use of available data that may lead to elucidating fundamental processes in the coupled system. The adequate performance of ocean models depends crucially on the forcing at sea surface that makes the analysis of the sea surface fluxes quite necessary.

Global atmospheric analyses carried out with grid resolutions in the order of $1^{\circ}$ give reliable estimates on the global scale. Our hypothesis here is that data from the atmospheric analysis give as well correct regional estimates since they are consistent with a large number of meteorological characteristics and processes accounted for in the analysis procedure. However, whether this is the case on the regional scale needs to be investigated and will be carried out in the following for the Black Sea region. In a first study using atmospheric analysis to estimate the heat fluxes in the Black Sea and the corresponding response of water masses, Staneva et al. (1995) and Stanev et al. (1995) used the NCEP data for the period 1980-1986. Several problems were encountered in these earlier analysis: (1) The NCEP data were rather coarse for the region since they were gridded with $1^{\circ}$ resolution, but this was actually a result of interpolation of $2^{\circ}$ data (Trenberth and Olson, 1998a,b). (2) The mean atmospheric characteristics, derived from the NCEP data (atmospheric temperature and relative humidity), showed large differences from climatological data (Staneva and Stanev, 1998). (3) The drawbacks in the data necessitated to correct their climatology before using them as forcing functions in ocean models and to diagnose heat fluxes.

The ECMWF data from the European re-analysis project (ERA) found recently a wide application in ocean modeling for constructing the sea surface boundary conditions. Detailed validations for the global scale were, e.g., presented during the 1st WCRP International Reanalysis Conference (Anonymous, 1998). The resolution of this data (T106 that corresponds approximately to $1.1^{\circ}$ ) and their quality for the global scale is quite good. This was the motivation to analyse their quality and consistency with earlier estimates on the regional scale for the
Black Sea region. Unlike in the preceding studies, where near surface data from atmospheric analysis and sea surface temperatures (observed or simulated by the ocean models) were used to calculate fluxes, we will provide here a diagnosis of the ECMWF data for the period $1979-1993$ as they are. This is a natural first step that can give answers to several fundamental questions: (1) How does the global re-analysis "see" the air-sea interaction in one small and very specific region? (2) How coherent is this "view" with the existing estimates? (3) What are the major drawbacks and could they be corrected in future re-analysis? (4) What are the perspectives of using the ERA data when driving coupled regional atmospheric and Black Sea models?

Our main interest in this paper will be to demonstrate the quality of ECMWF data as a potential forcing for Black Sea modeling. Thus, the main focus of our investigation are the fluxes at sea surface. More extended analysis of ECMWF data, including surface characteristics as temperature, humidity, winds, cloudiness, etc., and full set of plots of their horizontal patterns can be found in the report of Schrum et al. (2001).

\section{General information about the ERA data}

The European Center of middlefrist weather forecast runs operationally an analysis and forecast model to provide gridded global atmospheric data. Since the analysis and forecast models have been changed many times from the beginning of the operational analysis, the resulting long-year data set is highly heterogeneous and is thus not suitable to describe climate variability of the atmosphere. This was the motivation to set up the ECMWF re-analysis project to provide a consistent global 3-d atmospheric data set. The re-analysis has been carried out with a 'frozen' version of the data assimilation system for the hindcast period from 1979 to 1993 . The main features of the assimilation scheme can be characterized as follows: the horizontal resolution corresponds to the spectral wave number T106, which is about $1.1^{\circ}$. Thirty-one hybrid vertical levels have been chosen and the time stepping of the model output corresponds to $6 \mathrm{~h}$, i.e. four times daily. As a lower 
boundary for the SST, the SST and sea ice data from the GISST data set of the U.K. Met. Office (UKMO, 1980, 1981) and from the weekly SST analysis of Reynolds and Smith (1994, for the rest of the hindcast period) have been used. Furthermore, sea ice was derived from satellite data (SMMR and SSM/I). More details about the re-analysis project of the ECMWF were given by Gibson et al. (1996). Available are the initialized analyses as well as forecasts from the analysis. The set of parameter comprises the directly measured atmospheric data like the air pressure and air temperature as well as derived parameter like the air-sea fluxes. The following investigations are based only on the bottom forecasts with six hourly resolution, the model output data are mean values for the respective $6 \mathrm{~h}$.

\section{Heat balance estimates}

In the following, the fluxes at the sea surface given by the ECMWF and their consistency with earlier estimates (Makerov, 1961; Golubeva, 1984; Efimov and Timofeev, 1990; Simonov and Altman, 1991; Staneva et al., 1995) will be investigated. Most of these earlier studies used directly, or indirectly all, in the former Soviet Union, available information based on measurements in coastal stations and ship observations from the beginning of the 20th century. They demonstrated that the net air-sea heat exchange is a small number compared to the amplitude of seasonal oscillations. While this is roughly the case in most oceanic regions of the temperate climatic zone, the Black Sea shows some

Table 1

Climatological characteristics of ECMWF reanalysis data for the period 1979-1993

\begin{tabular}{|c|c|c|c|c|c|c|c|c|}
\hline $\begin{array}{l}\text { Variable (see below } \\
\text { the notations) }\end{array}$ & Units & $\begin{array}{l}\text { Number in } \\
\text { ECMWF } \\
\text { archive }\end{array}$ & $\begin{array}{l}\text { Mean } \\
\text { value }\end{array}$ & $\begin{array}{l}\text { Spatial } \\
\text { rms }\end{array}$ & $\begin{array}{l}\text { Basin mean } \\
\text { minimum }\end{array}$ & $\begin{array}{l}\text { Basin mean } \\
\text { maximum }\end{array}$ & $\begin{array}{l}\text { Basin mean } \\
\text { absolute } \\
\text { minimum }\end{array}$ & $\begin{array}{l}\text { Basin mean } \\
\text { absolute } \\
\text { maximum }\end{array}$ \\
\hline \multirow[t]{2}{*}{ Spr } & $\mathrm{mm} /$ year & 142 & 290 & 440 & & & & \\
\hline & $\mathrm{mm} / \mathrm{month}$ & & & & 63 & 528 & 23 & 762 \\
\hline $\mathrm{Cpr}$ & $\mathrm{mm} /$ year & 143 & 160 & 340 & & & & \\
\hline $\mathrm{spr}+\mathrm{cpr}$ & $\mathrm{mm} /$ month & & & & 114 & 750 & 45 & 1120 \\
\hline \multirow[t]{2}{*}{ |evp| } & $\mathrm{mm} /$ year & 182 & 700 & 330 & & & & \\
\hline & $\mathrm{mm} /$ month & & & & 134 & 1129 & 83 & 1443 \\
\hline \multirow[t]{2}{*}{$\mathrm{spr}+\mathrm{cpr}-|\mathrm{evp}|$} & $\mathrm{mm} /$ year & & -250 & 880 & & & & \\
\hline & $\mathrm{mm} / \mathrm{month}$ & & & & -579 & 798 & -263 & 1182 \\
\hline $\operatorname{Ssr}-(|\operatorname{str}|+|\operatorname{ssh}|+|\operatorname{slh}|)$ & $\mathrm{W} \mathrm{m}^{-2}$ & & 6 & 50.25 & -147 & 159 & -236 & 180 \\
\hline Wind stress magnitude & $\mathrm{Pa} 10^{-1}$ & $180 / 181$ & 0.53 & 0.34 & 0.21 & 1.0 & 0.14 & 1.3 \\
\hline \multicolumn{9}{|l|}{ Scalars } \\
\hline Msl & $\mathrm{HPa}$ & 151 & 1016.2 & 1.79 & 1011 & 1022 & 1009 & 1024 \\
\hline Tcc & & 164 & 0.45 & 0.3 & 0.17 & 0.72 & 0.10 & 0.82 \\
\hline Wind magnitude & $\mathrm{m} \mathrm{s}^{-1}$ & $165 / 166$ & 4.7 & 1.7 & 3.4 & 6.2 & 2.9 & 6.7 \\
\hline $2 t_{-}$ & ${ }^{\circ} \mathrm{C}$ & 167 & 13.4 & 1.81 & 4.3 & 23.2 & 1.1 & 24.7 \\
\hline $2 d_{-}$ & ${ }^{\circ} \mathrm{C}$ & 168 & 10.1 & 1.83 & 1.07 & 19.6 & -2.6 & 20.6 \\
\hline Sst & ${ }^{\circ} \mathrm{C}$ & 235 & 14.4 & 1.01 & 6.71 & 23.55 & 5.64 & 24.73 \\
\hline Humidity & $\%$ & & 81.1 & 8.5 & 75.6 & 85.8 & 70.5 & 87.2 \\
\hline
\end{tabular}

Notations: spr-stratiform precipitation, $\mathrm{cpr}$-convective precipitation, evaporation, ssr-shortwave radiation, str-surface thermal radiation, ssh-sensible heat flux, slh-latent heat flux, msl-mean sea level pressure, tcc-total cloud cover, 2t_-2-m temperature, $2 d_{-}-2-m$ dew point, sst_-skin temperature. 
peculiarities: (1) The horizontal heat transport in open ocean areas with dimensions comparable to the Black Sea is orders of magnitudes larger than the heat exchange in the Bosphorus Straits. (2) The divergence/convergence of surface heat flux at the ocean surface is associated with large horizontal (meridional) transport and has an important climatic impact. The corresponding transport in the Black Sea is much smaller (Stanev, 1988). (3) The restricted conditions in the Straits of Bosphorus constrain the total heat content in the Black Sea and make the surface heat flux to a major component in the heat balance (this is roughly the case in other inland basins, as the Baltic Sea, e.g. Schrum and Backhaus, 1999). Below, we will briefly analyse some peculiarities of the heat flux components and investigate the fluxes given by the ECMWF re-analysis.

The solar radiation (with a maximum in June, and a minimum in December) has the strongest contribution to the total heat flux at the sea surface (Table 1).
Its temporal variability is caused not only by astronomical factors, but also by the seasonal variability in the cloudiness (Fig. 4f). In a small basin, as the Black Sea, the radiation conditions are relatively uniform in space, but not in time. The spatial variability is much larger from April to August, while in the rest of the year the radiation conditions are more uniform. The variability in the basin mean solar radiation computed from the ECMWF data and the one discussed by Golubeva (1984) and Simonov and Altman (1991) are in a good agreement. The mean values are about $150 \mathrm{~W} \mathrm{~m}^{-2}$ (Tables 1 and 2). Much smaller are the basin mean values of backward radiation $\left(-70.7 \mathrm{~W} \mathrm{~m}^{-2}\right)$, but they are also comparable with the climatic estimates (Table 2), the discrepancy is only in the order of $5 \%$ of the ECMWF values. The latent heat flux minimum in spring is associated with the small wind magnitudes during this season. The basin mean value $\left(-55.4 \mathrm{Wm}^{-2}\right)$ is smaller than the climatic data. The differences are in the

Table 2

Climatological estimates from different origins

\begin{tabular}{|c|c|c|c|}
\hline Variable & Units & Mean value & \\
\hline \multicolumn{4}{|l|}{ Heat fluxes } \\
\hline & & Makerov (1961) & Simonov and Altman (1991) \\
\hline Ssr & $\mathrm{W} \mathrm{m}{ }^{-2}$ & 140 & 150 \\
\hline$|\operatorname{str}|$ & $\mathrm{W} \mathrm{m}{ }^{-2}$ & 66.2 & 65.7 \\
\hline$|\mathrm{Ssh}|$ & $\mathrm{W} \mathrm{m} \mathrm{m}^{-2}$ & 10.4 & 14.3 \\
\hline$|\operatorname{slh}|$ & $\mathrm{W} \mathrm{m^{-2 }}$ & 62.5 & 73.3 \\
\hline $\operatorname{Ssr}-(|\operatorname{str}|+|\operatorname{ssh}|+|\operatorname{slh}|)$ & $\mathrm{W} \mathrm{m}^{-2}$ & 5.4 & -0.3 \\
\hline \multicolumn{4}{|l|}{ Water fluxes } \\
\hline & & Sorkina (1974)/Makerov (1961) & MHI \\
\hline $\mathrm{spr}+\mathrm{cpr}$ & $\mathrm{mm} /$ year & 520 & 580 \\
\hline |evp| & $\mathrm{mm} /$ year & 731 & 780 \\
\hline \multicolumn{4}{|l|}{ Wind stress } \\
\hline & & Sorkina (1974) & MHI \\
\hline Magnitude & $\mathrm{Pa} 10^{-1}$ & 0.26 & 0.19 \\
\hline \multicolumn{4}{|l|}{ Scalars } \\
\hline & & Sorkina (1974) & MHI \\
\hline $2 t_{-}$ & ${ }^{\circ} \mathrm{C}$ & 13.54 & 13.41 \\
\hline $2 \mathrm{~d}_{-}$ & ${ }^{\circ} \mathrm{C}$ & 12.05 & 13.15 \\
\hline Humidity & $\%$ & 80.35 & 80.11 \\
\hline Wind speed & $\mathrm{m} \mathrm{s}^{-1}$ & 5 & 1.12 \\
\hline Tcc & & 0.53 & 0.55 \\
\hline
\end{tabular}

MHI_data kindly made available by Yu. Golubev from Marine Hydrophysical Institute, Seavastopol, for the rest of the notations, see Table 1. 
(a)

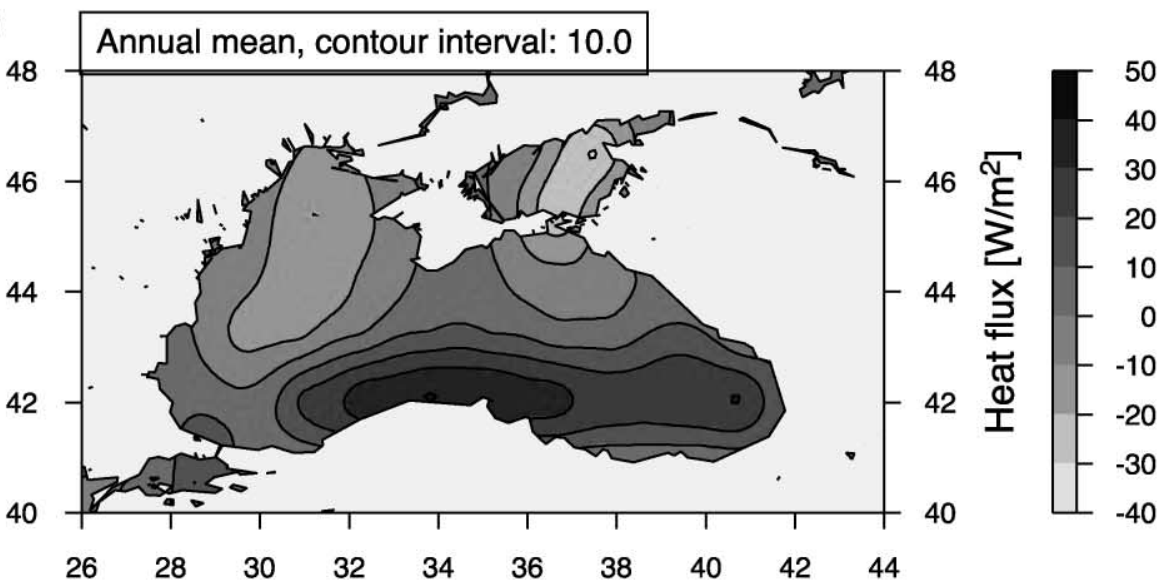

(b)

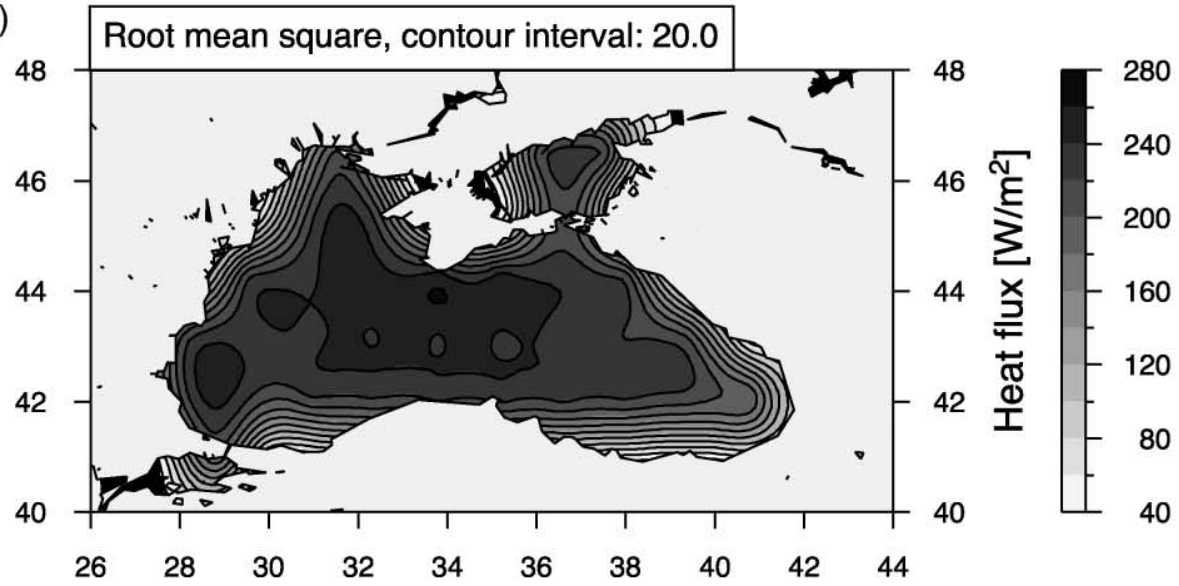

(c)

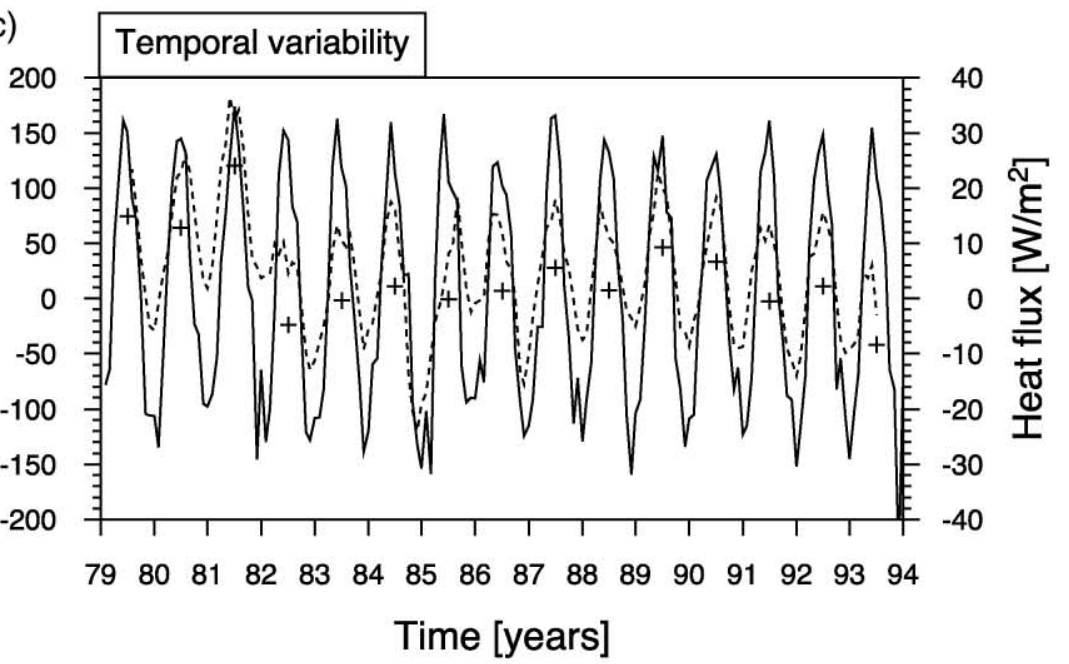

Fig. 1. Annual mean total heat flux (a), rms of the heat flux (b), and temporal variability (c) in the heat flux resolved by the monthly mean values averaged over the whole sea surface; solid line: monthly values, dashed line: moving average over one seasonal cycle. The units are $\mathrm{W} / \mathrm{m}^{2}$. 
order of $15-35 \%$. The sensible heat is the smallest component in the Black Sea heat balance $(-14 \mathrm{~W}$ $\mathrm{m}^{-2}$ ). Its variability is subject to large fluctuations due to extreme wind conditions as this was the case in 1985 and 1993 (see Fig. 4b).

The mean thermal exchange between atmosphere and ocean (Fig. 1a) for the period 1979-1993 reveals cooling in the northern part of the sea and warming along the southern coast of almost equal magnitude (up to $50 \mathrm{~W} \mathrm{~m}^{-2}$ ). The resulting conclusion, that the sea gains heat along its southern coast and transfers heat to the atmosphere in its northern area, is in agreement with earlier results of Golubeva (1984). Obviously, the transport of heat due to divergences in the ocean column is from south to north. We can thus compute the total heat flux entering the sea at particular zonal bands. Integrating these zonally integrated fluxes starting from the southern boundary (the small value of the heat transport through the Strait of Bosphorus is neglected) to any particular latitude gives a measure of the meridional heat transport. The maximum northward heat transport estimated from the ECMWF data of $0.002 \mathrm{PW}$ (at $42^{\circ} 10^{\prime} \mathrm{N}$ ) matches well the estimated transports calculated by Stanev (1990), where the heat flux data of Makerov (1961) had been used. Comparing this number to the transport in the Atlantic ocean at the same latitude of about $2 \mathrm{PW}$ we see that per zonal unit distance $(1000 \mathrm{~km}$ in the Black Sea against 6000 $\mathrm{km}$ in the Atlantic ocean) the transport in the Black Sea is 100 times smaller than in the ocean. This proves that the climatic impact of the Black Sea (seen as the transport of heat from the south to north) is strongly reduced compared to the open ocean case, due to the very shallow response of its thermal structure to the atmospheric forcing (c.f. Section 1).

The main result of the analysis from the investigation of the total heat balance is that the horizontal contrast in the annual mean heat flux (rms of 50.25 $\mathrm{W} \mathrm{m} \mathrm{m}^{-2}$ ) is larger than the contrast in every individual component of the heat balance (Table 1). The spatial variability is, however, more than two times smaller as the variability in the basin averaged monthly mean heat flux and substantially smaller than the variability caused by short-time processes (compare Fig. 1b and c). As seen in Fig. 4a, the air-sea exchange in the coastal region is much smaller than in the open sea revealing the reduced thermal capacity of the shallow sea.

The seasonal variability of total heat flux compares well to the estimates of Simonov and Altman (1991) and Staneva and Stanev (1998): the sea gains maximum heat in May and its heat release to the atmosphere is at maximum in December and January. Thus, though the horizontal patterns are different from climatic ones, the general climatic characteristics (means and seasonal amplitudes) of different data sets are not too different, the latter giving confidence when using the ECMWF data to force ocean models (at least for simulations of the seasonal cycle).

Ending this section, we will remind that the net heat flux in the climatological data of Makerov (1961) is $5.4 \mathrm{~W} \mathrm{~m}^{-2}$ and the net heat flux estimated from the ERA data is $6 \mathrm{~W} \mathrm{~m}^{-2}$. Having in mind that these are very small numbers compared to extreme heat fluxes $\sim 200 \mathrm{~W} \mathrm{~m} \mathrm{~m}^{-2}$ and that no precise estimates of heat fluxes exist, we could conclude that the ECMWF data give quite reasonable net heat flux values.

\section{Precipitation and evaporation}

It is well known that one of the unresolved problems in atmospheric modeling is to correctly replicate the precipitation patterns (the coarse resolution of the models makes it impossible to account for the patchiness of precipitation, for instance). Thus, the parallel analysis of climatic data and data obtained from the ECMWF re-analysis could actually serve to address not only purely oceanographic issues, but could give an idea about the ability of atmospheric models to describe the precipitation in the region. This is of utmost importance when using coarse resolution data to force regional models. In this section, we will demonstrate how well the ECMWF data match climatic ones and will use as illustration precipitation minus evaporation data (Fig. 2).

About one third of all precipitation is due to convective precipitation and two thirds to stratiform precipitation (Table 1). The horizontal pattern of precipitation (not shown here) is dominated by a maximum reaching $1 \mathrm{~m} \mathrm{year}^{-1}$ that is localized in 
(a)

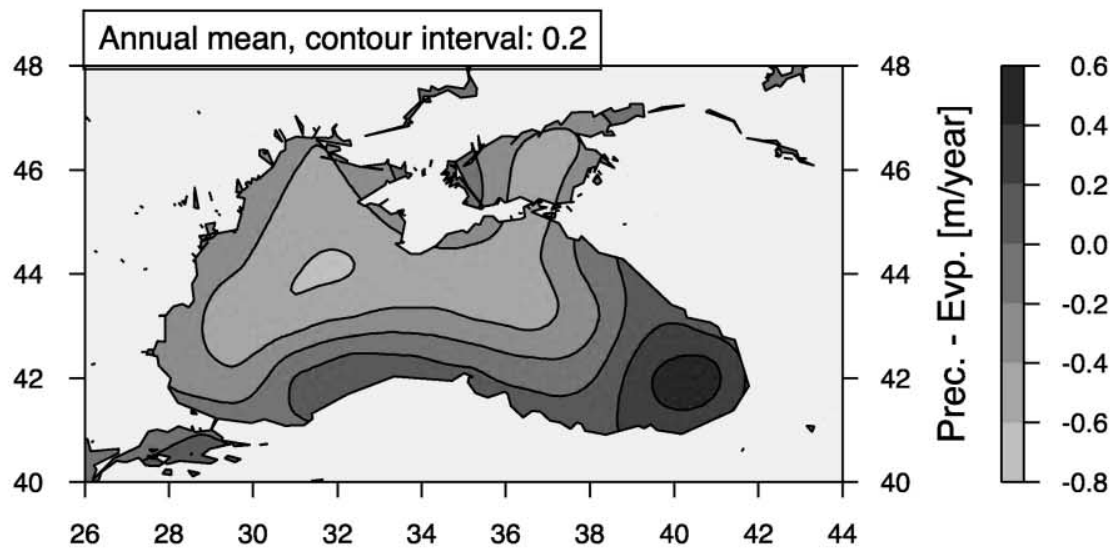

(b)
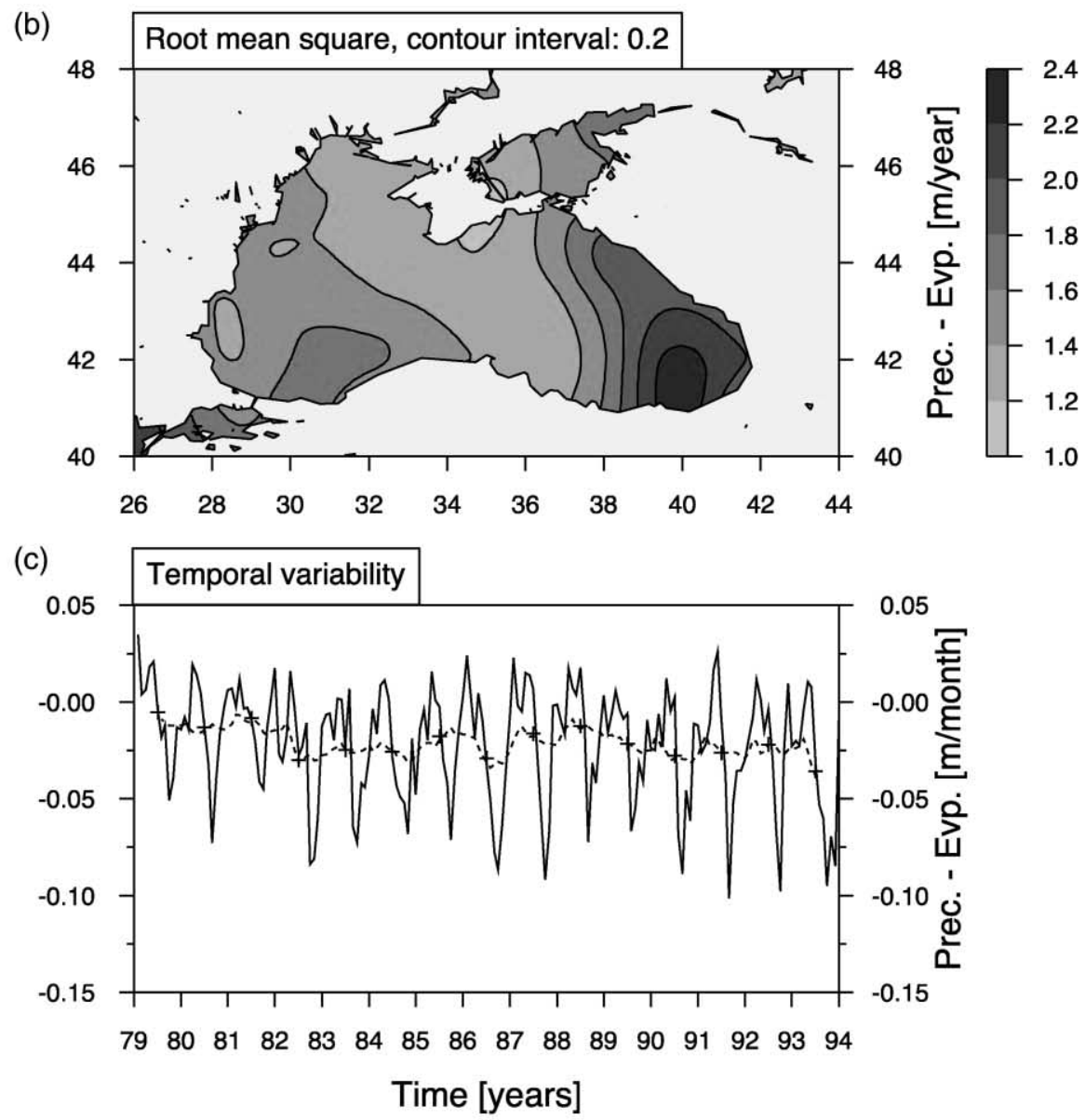

Fig. 2. Annual mean of precipitation minus evaporation (a), rms of precipitation minus evaporation (b), and temporal variability (c) of the water flux (p-e) resolved by the monthly values averaged over the whole sea surface; solid line: monthly values, dashed line: moving average over one seasonal cycle. The units are $\mathrm{m} /$ year $(\mathrm{a}, \mathrm{b})$ and $\mathrm{m} / \mathrm{month}(\mathrm{c})$. 
the easternmost corner. The large precipitation in the southern Black Sea is associated with the main paths of atmospheric cyclones. Its enhancement in the eastern sub-basin is orographically induced. The basin mean precipitation from ECMWF analysis $(0.45 \mathrm{~m})$ is underestimated compared to climatic data $(0.57 \mathrm{~m})$.

Most precipitation occurs during the winter months (December-February). Largest values (about $0.2 \mathrm{~m} \mathrm{month}^{-1}$ ) are observed in the easternmost Black Sea in July and August. However, this appearance is very irregular and the seasonal signal is masked by the variability on shorter and longer time scales.

The evaporation pattern (also not shown here) shows roughly an inverse structure compared to precipitation: the largest evaporation (of about 800-1000 $\mathrm{mm}$ ) is located in the northern Black Sea (where the precipitation is at minimum), caused by the strong local winds there. In contrary, the evaporation minimum is observed in the easternmost Black Sea, where the precipitation is at maximum. Thus, the precipitation minus evaporation gives a pattern that is similar to the those of the two basic fields (Fig. 2). This figure gives an idea about the spatial distribution of the buoyancy flux due to fresh water exchange between sea and atmosphere. It shows dilution in the eastern and southern region and concentration of salt in the rest of the basin.

The spatial pattern associated with the zones of the largest temporal variability follows approximately the pattern of annual mean evaporation: the largest variability is observed where the evaporation has a maximum. However, the variance pattern is meridionally elongated, which is not observed in the precipitation less evaporation pattern. The temporal variability of precipitation less evaporation (Fig. 2c) shows more pronounced seasonality than the precipitation field and the magnitude of oscillations is about 1.5-2 times larger than in the basin mean precipitation. The annual mean precipitation minus evaporation is $-0.25 \mathrm{~m}$ (this is in the order of estimates from climatic data). Thus, the air-sea water exchange in the Black Sea has the same sign as in the neighboring Mediterranean Sea. However, what makes the two basins quite different is the river runoff that exceeds the vapor exchange at sea surface and makes the Black Sea estuarine-type basin.

\section{Wind stress}

A major problem in the previous computations of wind stress was the bad data coverage that necessitated the extrapolation of data, particularly along the southern coasts (the possible errors resulting from extrapolations are discussed in the work of Staneva and Stanev, 1998). The situation seems much better when dealing with atmospheric analysis since the data extrapolation in the regions with bad data coverage is dynamically consistent. This gives a possibility to verify here the climatic estimates based on atmospheric analysis in the northern Black Sea (where the data sampling is good) and to reconsider the earlier climatic wind stress estimates in the southern Black Sea (where the data coverage is really poor) by comparing them with the data from the ECMWF re-analysis. In the context of inter-comparison data of different origins, it is noteworthy that the analysis of Staneva and Stanev (1998) demonstrates that the magnitude of seasonal oscillations is strongly underestimated by the NCEP data. We will carry out the same analysis for the ECMWF data.

The mean wind stress pattern follows approximately the one of the surface winds and demonstrates good agreement with climatological data compiled by Staneva and Stanev (1998). The wind stress pattern (Fig. 3) is dominated by northerly winds in the northern Black Sea. The summer pattern is dominated by the Azores high causing the westerly component. Easterly wind forcing prevails off the Caucasian coast, resulting in a large curl there. In the latter area, the temporal variability is much smaller than in the western Black Sea (Fig. 3b), therefore, the cyclonic curl is well pronounced during most of the year. These peculiarities in the wind stress patterns are supported by the climatological data and would ensure the cyclonic curl, forcing the cyclonic circulation in the Black Sea. This forcing acts in the same direction as the fresh water forcing (dilution of coastal zone by river runoff and extremely high precipitation in the easternmost area) and opposes the dynamic effect of surface heating.

The amplitude of the seasonal cycle based on the ECMWF data is much higher than that estimated from the NCEP data and is comparable to estimates from climatic data. Similar to the temporal variability derived from climatic data (Staneva and Stanev, 
(a)

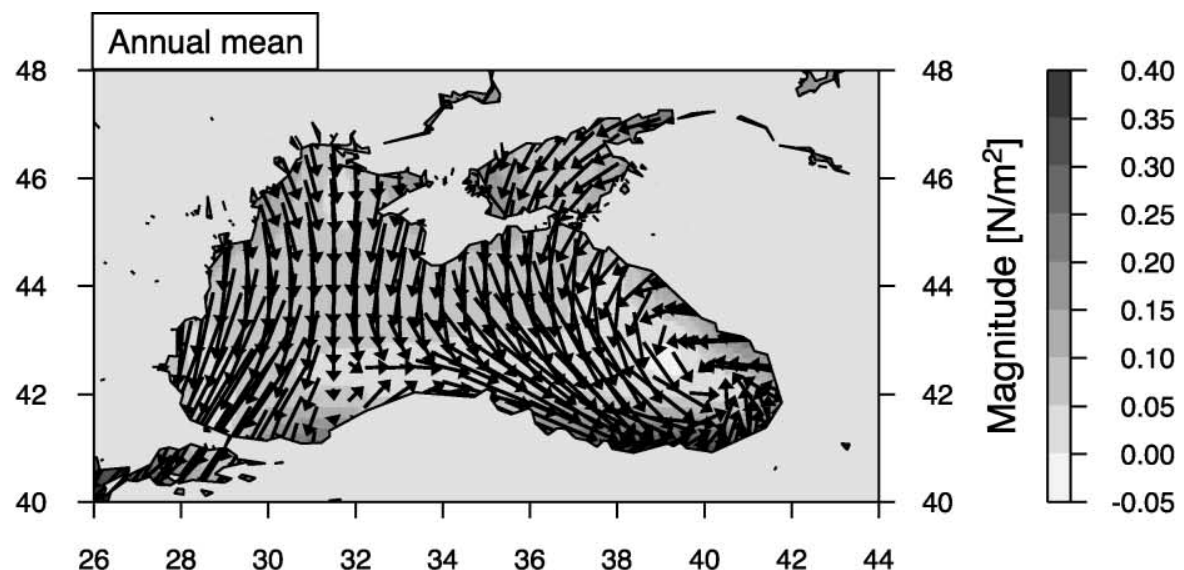

(b)

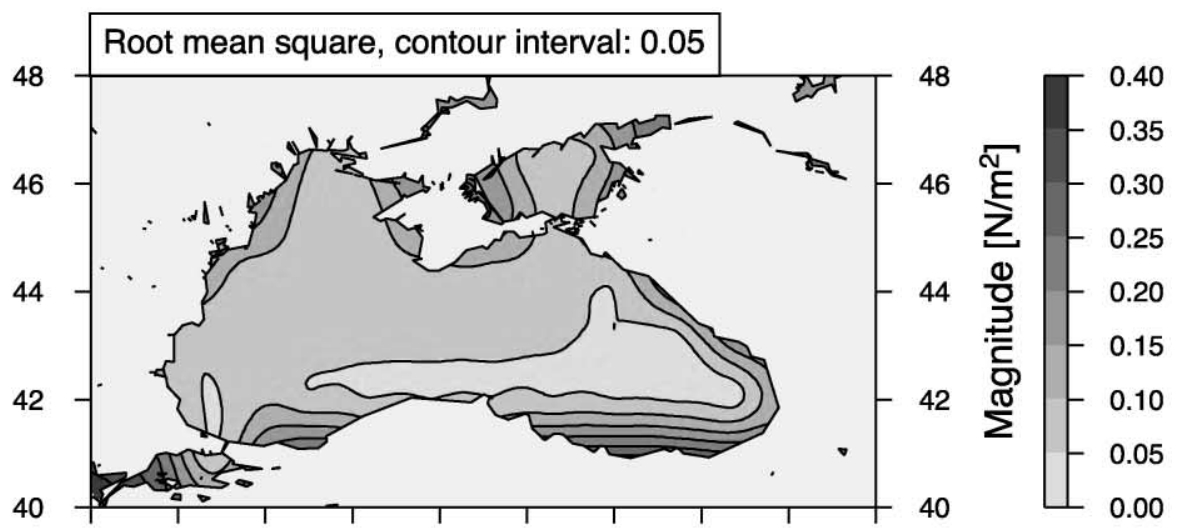

(c)
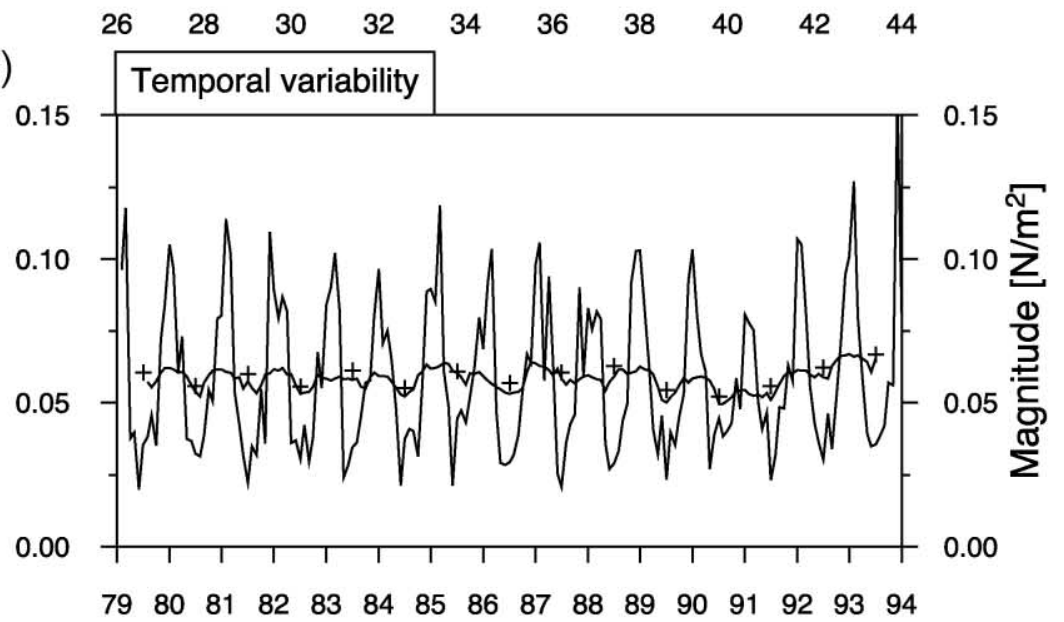

Time[Years]

Fig. 3. Annual mean wind stress (a), rms of the wind stress (b), and temporal variability (c) of the mean wind stress resolved by the monthly values averaged over the whole sea surface; solid line: monthly values, dashed line: moving average over one seasonal cycle. The units are $\mathrm{N} / \mathrm{m}^{2}$. 
1998), where the annual wind variability is characterized by two maxima (January and September) and two minima (in May and in November), this structure is reflected by the ECMWF data. This also agrees well with climatic estimates, based on analysis from UKMO with higher resolution for the period 1993-1996. However, from Fig. 3c it becomes clear that occasionally the bi-modal structure is missing and only a one-modal seasonal signal can be found in the wind forcing. It is noteworthy that in some years (December 1985 and December 1993), the wind stress magnitude attains extremely large values. The latter event is known to have induced large cold water formation (Ivanov, 1998) and is supported by the large cooling at the same time, as it can be seen in the ECMWF net sea surface heat flux (Fig. 1c).

\section{Seasonal fluxes}

In order to compare and assess the regional differences in seasonal fluxes, we averaged the data over the entire Black Sea (BL), as well as its sub-regions consisting of the western (WB) and eastern (EB) basins, the northwest shelf (NWS) and the Azov Sea (AZ) delineated in Fig. 4. In contrast to the previous investigations, the gridded data from the ECMWF (gridded on a $1^{\circ} \times 1^{\circ}$ grid) were used for the following investigations, to ensure uniform sub-regions. Thus, small differences can be found for the estimates of annual mean fluxes (Tables 1 and 3) caused by the gridding and connected interpolation. The monthly mean fluxes of heat and water, obtained from the gridded ERA data set 1979-1993 and averaged over the Black Sea marine area, are shown in Fig. 5. The long wave back-radiation shows no pronounced seasonality. Only a slight increase in early autumn and a decreasing tendency towards the winter, mainly as a function of mean cloudiness and sea surface temperature, can be found. The sensible heat flux component is much smaller than either the long wave or the latent heat flux, with a minimum in summer when the air-sea temperature contrast reaches minimum values. The latent heat flux reaches a maximum in September at the time of maximum wind speeds, and is at minimum in summer. The latent heat transfer imprints its effect on the total outgoing flux from the sea-surface (the sum of the preceding components). When combined with the incoming short-wave flux at the surface, the net heat flux varies from a maximum net heat gain of the sea in May to a maximum heat loss in November.

The regional breakdown of seasonal fluxes is given in Table 4 . The long wave radiation losses are

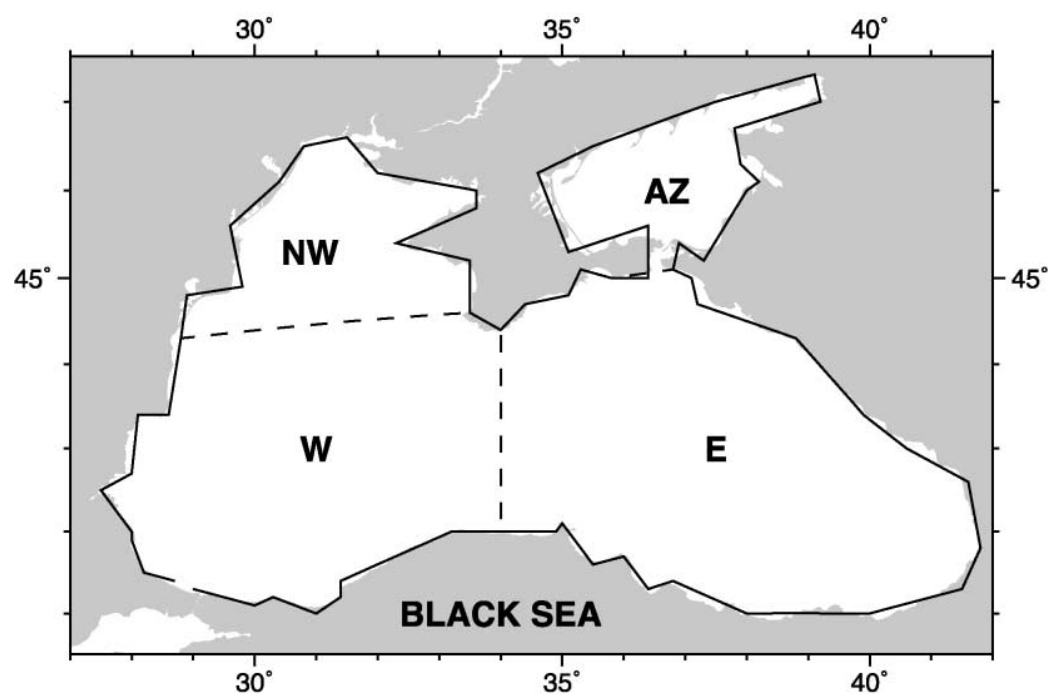

Fig. 4. Black Sea sub-regions used for the seasonal evaluation of the fluxes. 
Table 3

Annual heat and water fluxes in sub-regions of the Black Sea based on the $1^{\circ} \times 1^{\circ}$ gridded ERA data

\begin{tabular}{|c|c|c|c|c|c|c|c|c|c|}
\hline Annual & $\begin{array}{l}\text { |str| } \\
\left(\mathrm{W} / \mathrm{m}^{2}\right)\end{array}$ & $\begin{array}{l}|\mathrm{Ssh}| \\
\left(\mathrm{W} / \mathrm{m}^{2}\right)\end{array}$ & $\begin{array}{l}|\mathrm{slh}| \\
\left(\mathrm{W} / \mathrm{m}^{2}\right)\end{array}$ & $\begin{array}{l}(|\operatorname{str}|+|\operatorname{ssh}|+|\operatorname{slh}|) \\
\left(\mathrm{W} / \mathrm{m}^{2}\right)\end{array}$ & $\begin{array}{l}\text { Ssr } \\
\left(\mathrm{W} / \mathrm{m}^{2}\right)\end{array}$ & $\begin{array}{l}\mathrm{Ssr}-(|\mathrm{str}|+|\mathrm{ssh}|+|\operatorname{slh}|) \\
\left(\mathrm{W} / \mathrm{m}^{2}\right)\end{array}$ & $\begin{array}{l}\text { levp } \mid \\
(\mathrm{mm} / \text { day })\end{array}$ & $\begin{array}{l}\mathrm{spr}+\mathrm{cpr} \\
(\mathrm{mm} / \text { day })\end{array}$ & $\begin{array}{l}|\mathrm{evp}|-(\mathrm{spr}+\mathrm{cpr}) \\
(\mathrm{mm} / \text { day })\end{array}$ \\
\hline NW Shelf & 69.067 & 22.406 & 57.957 & 149.430 & 137.915 & -11.515 & 2.002 & 0.785 & 1.217 \\
\hline Azov Sea & 66.231 & 21.880 & 53.821 & 141.932 & 130.499 & -11.433 & 1.854 & 0.968 & 0.886 \\
\hline Western Black Sea & 70.530 & 14.697 & 58.700 & 143.927 & 148.332 & 4.405 & 2.028 & 1.059 & 0.969 \\
\hline Eastern Black Sea & 71.078 & 11.365 & 49.892 & 132.335 & 144.460 & 12.125 & 1.715 & 1.286 & 0.429 \\
\hline Total Black Sea & 70.086 & 15.251 & 54.597 & 139.934 & 143.422 & 3.488 & 1.882 & 1.098 & 0.784 \\
\hline
\end{tabular}




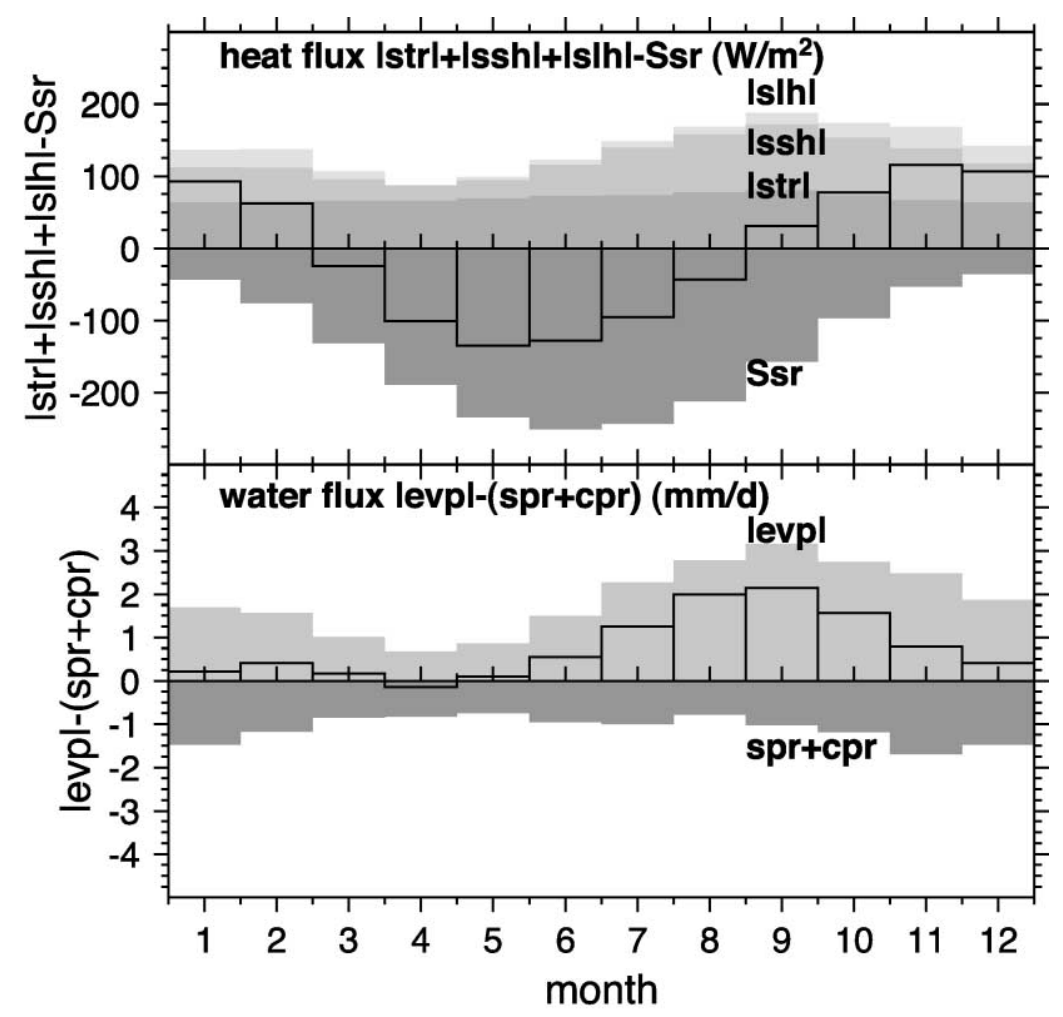

Fig. 5. Monthly mean heat $\left(\mathrm{W} / \mathrm{m}^{2}\right)$ and water fluxes (mm/day) in the Black Sea.

relatively uniform, with a slight decrease in the Azov Sea especially in winter. The sensible heat fluxes are larger in the northern regions in spring and summer. The latent heat fluxes vary irregularly between subregions, while the incoming solar radiation shows higher values in the southern regions relative to the northern parts. The net annual heat flux, as a result of the above components, corresponds to maximum loss to the atmosphere in the NWS and WB regions in winter, and maximum gain of heat in the EB in summer. The net annual heat flux is from the ocean to the atmosphere in the northern regions of AS and NWS, and in the reverse direction in the EB and WB regions, yielding a net annual budget close to zero for the entire basin (c.f. Section 3).

Annually, the highest precipitation takes place in the EB and exceeds the lowest values in the NWS by more than $50 \%$. Seasonally, the highest precipitation occurs in the winter months in the EB, when it attains a value that is almost twice than that of the NWS. On the other hand, the maximum precipitation occurs in winter in the WB. As compared to the EB and the WB, the NWS and AS in the north display weaker seasonality in precipitation; the maximum occurs in autumn at the NWS and in summer at the AS areas.

The annual evaporation values are relatively more uniform in all sub-regions of the Black Sea, with larger values in the WB and NWS as compared to the AS and the EB. The maximum evaporation takes place in autumn in relation to increased winds during the same period, except in the Azov Sea where the maximum evaporation is in summer.

The net surface flux of water $(\mathrm{E}-\mathrm{P})$ for the entire Black Sea amounts to $0.78 \mathrm{~mm} /$ day $=29 \mathrm{~cm} /$ year. The maximum value for the NWS $(1.22 \mathrm{~mm} /$ day $=$ $45 \mathrm{~cm}$ /year) is much larger than the minimum value found for the $\mathrm{EB}(0.43 \mathrm{~mm} /$ day $=16 \mathrm{~cm} /$ year $)$. 
Table 4

Seasonal heat and water fluxes in sub-regions of the Black Sea based on the $1^{\circ} \times 1^{\circ}$ gridded ERA data

\begin{tabular}{|c|c|c|c|c|c|c|c|c|c|}
\hline & $\begin{array}{l}|\mathrm{str}| \\
\left(\mathrm{W} / \mathrm{m}^{2}\right)\end{array}$ & $\begin{array}{l}|\mathrm{Ssh}| \\
\left(\mathrm{W} / \mathrm{m}^{2}\right)\end{array}$ & $\begin{array}{l}|\mathrm{slh}| \\
\left(\mathrm{W} / \mathrm{m}^{2}\right)\end{array}$ & $\begin{array}{l}(|\operatorname{str}|+|\operatorname{ssh}|+|\operatorname{slh}|) \\
\left(\mathrm{W} / \mathrm{m}^{2}\right)\end{array}$ & $\begin{array}{l}\mathrm{Ssr} \\
\left(\mathrm{W} / \mathrm{m}^{2}\right)\end{array}$ & $\begin{array}{l}\mathrm{Ssr}-(|\operatorname{str}|+|\operatorname{ssh}|+|\operatorname{slh}|) \\
\left(\mathrm{W} / \mathrm{m}^{2}\right)\end{array}$ & $\begin{array}{l}\text { evp| } \\
(\mathrm{mm} / \text { day })\end{array}$ & $\begin{array}{l}\mathrm{spr}+\mathrm{cpr} \\
(\mathrm{mm} / \text { day })\end{array}$ & $\begin{array}{l}|\mathrm{evp}|-(\mathrm{spr}+\mathrm{cpr}) \\
(\mathrm{mm} / \mathrm{day})\end{array}$ \\
\hline \multicolumn{10}{|l|}{ Winter } \\
\hline NW Shelf & 64.104 & 35.412 & 53.436 & 152.952 & 49.222 & -103.730 & 1.845 & 0.872 & 0.973 \\
\hline Azov Sea & 53.746 & 16.288 & 32.109 & 102.143 & 41.548 & -60.595 & 1.100 & 1.018 & 0.082 \\
\hline Western Black Sea & 67.444 & 27.221 & 57.483 & 152.148 & 54.752 & -97.396 & 1.986 & 1.362 & 0.624 \\
\hline Eastern Black Sea & 64.620 & 20.319 & 45.783 & 130.722 & 51.928 & -78.794 & 1.572 & 1.658 & -0.086 \\
\hline Total Black Sea & 64.412 & 24.544 & 49.618 & 138.574 & 51.453 & -87.121 & 1.709 & 1.372 & 0.337 \\
\hline \multicolumn{10}{|l|}{ Spring } \\
\hline NW Shelf & 64.952 & 11.566 & 28.469 & 104.987 & 176.630 & 71.643 & 0.983 & 0.689 & 0.294 \\
\hline Azov Sea & 66.799 & 19.165 & 38.178 & 124.142 & 169.341 & 45.199 & 1.317 & 0.815 & 0.502 \\
\hline Western Black Sea & 66.570 & 3.075 & 22.993 & 92.638 & 192.025 & 99.387 & 0.794 & 0.783 & 0.011 \\
\hline Eastern Black Sea & 69.080 & 2.973 & 21.136 & 93.189 & 185.858 & 92.669 & 0.726 & 0.874 & -0.148 \\
\hline Total Black Sea & 67.352 & 5.949 & 24.638 & 97.939 & 184.976 & 87.037 & 0.849 & 0.808 & 0.041 \\
\hline \multicolumn{10}{|l|}{ Summer } \\
\hline NW Shelf & 74.562 & 14.159 & 66.029 & 154.750 & 227.328 & 72.578 & 2.281 & 0.724 & 1.557 \\
\hline Azov Sea & 74.413 & 27.590 & 79.589 & 181.592 & 217.399 & 35.807 & 2.746 & 1.142 & 1.604 \\
\hline Western Black Sea & 74.921 & 5.229 & 62.991 & 143.141 & 243.318 & 100.177 & 2.176 & 0.746 & 1.430 \\
\hline Eastern Black Sea & 74.668 & 4.479 & 58.001 & 137.148 & 235.604 & 98.456 & 1.995 & 1.075 & 0.920 \\
\hline Total Black Sea & 74.716 & 8.564 & 63.188 & 146.468 & 235.233 & 88.765 & 2.179 & 0.915 & 1.264 \\
\hline \multicolumn{10}{|l|}{ Autumn } \\
\hline NW Shelf & 72.651 & 28.488 & 83.896 & 185.035 & 98.479 & -86.556 & 2.898 & 0.854 & 2.044 \\
\hline Azov Sea & 69.965 & 24.477 & 65.407 & 159.849 & 93.705 & -66.144 & 2.254 & 0.896 & 1.358 \\
\hline Western Black Sea & 73.184 & 23.263 & 91.332 & 187.779 & 103.232 & -84.547 & 3.155 & 1.343 & 1.812 \\
\hline Eastern Black Sea & 75.945 & 17.691 & 74.650 & 168.286 & 104.448 & -63.838 & 2.566 & 1.533 & 1.033 \\
\hline Total Black Sea & 73.864 & 21.946 & 80.944 & 176.754 & 102.028 & -74.726 & 2.791 & 1.300 & 1.491 \\
\hline
\end{tabular}




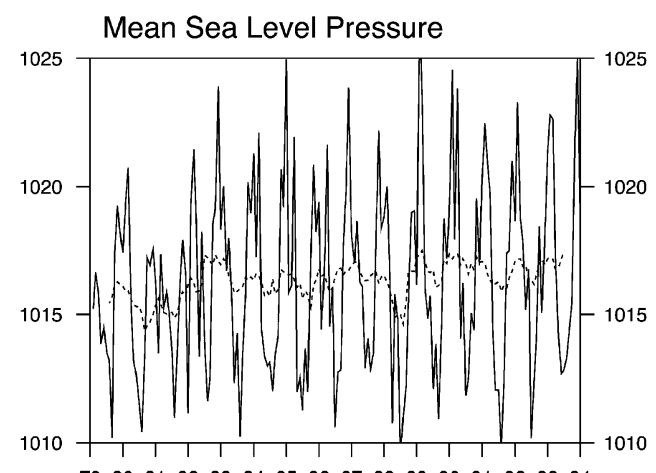

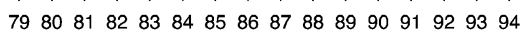
a Time [years]

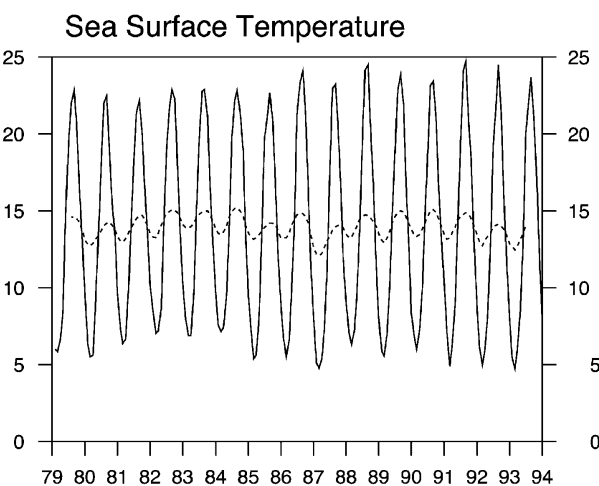

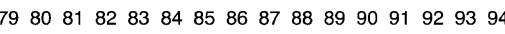
d
Time [years]

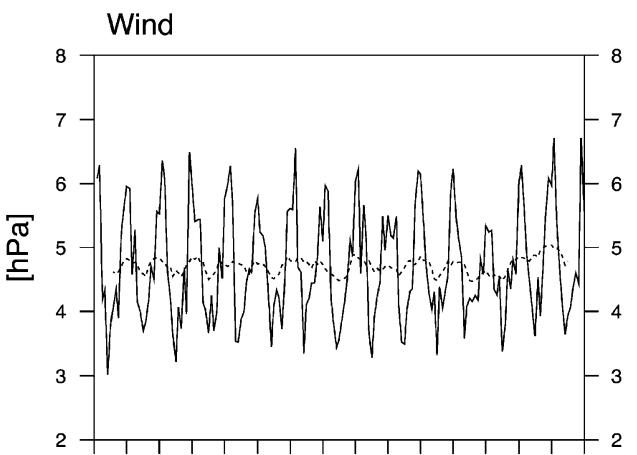

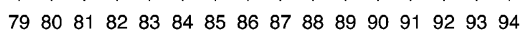

b Time [years]

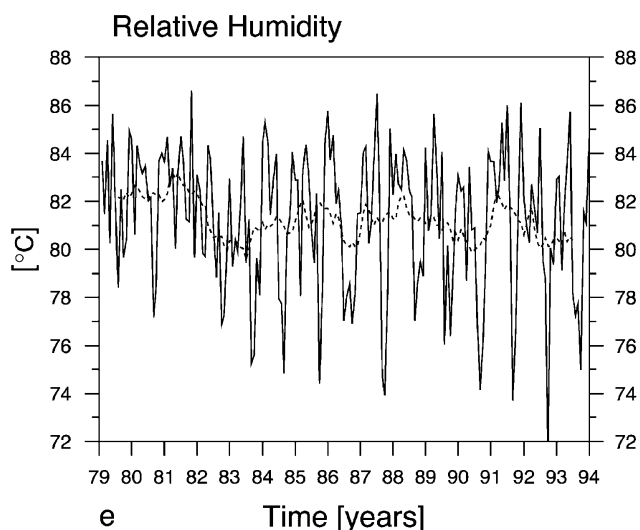

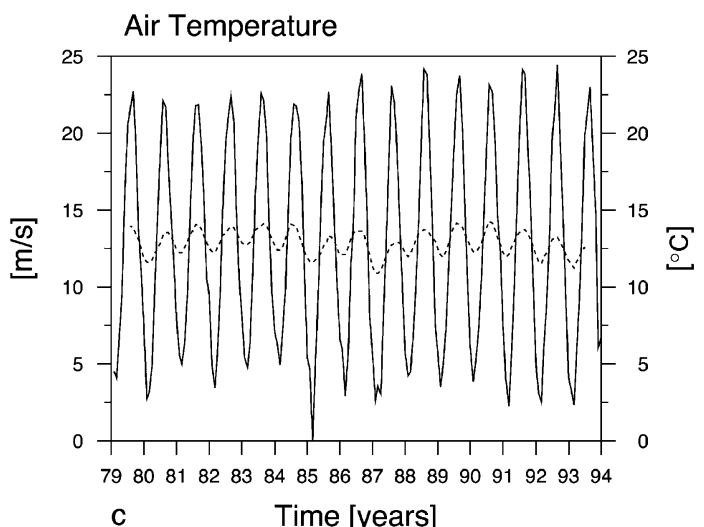

C Time [years]

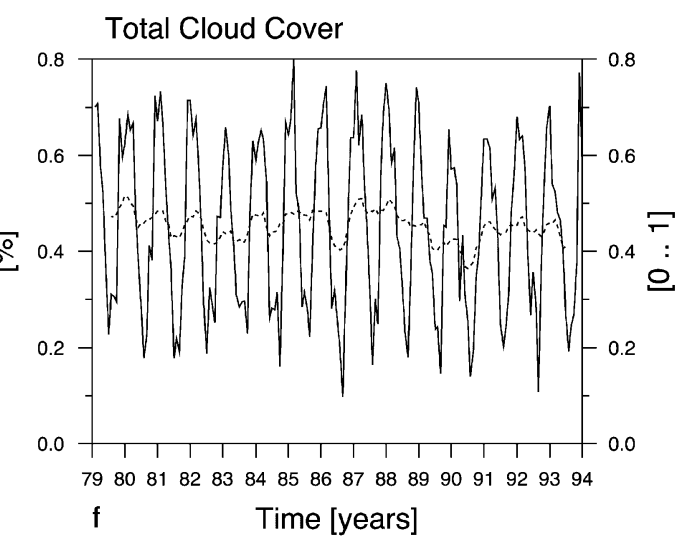

Fig. 6. Temporal variability for the period 1979-1993 plotted from the monthly mean data averaged over the entire Black Sea: solid line: monthly values, dashed line: moving average over one seasonal cycle. (a) Atmospheric pressure, (b) wind magnitude, (c) air temperature at 2 m, (d) sea surface temperature, (e) relative humidity, (f) cloudiness. 


\section{Temporal variability of near surface fields}

The examination of temperature and precipitation anomalies in large areas of the Northern hemisphere (Leetmaa et al., 1999) brings us to the conclusion that the region of the Black Sea (between $40^{\circ} 56^{\prime}-$ $46^{\circ} 33^{\prime} \mathrm{N}$ and $27^{\circ} 27^{\prime}-41^{\circ} 42^{\prime}$ ) is strongly affected by the North Atlantic Oscillation (NAO). Several important meteorological centers of action induce the local anomalies of atmospheric pressure: the Azores high (having a dominating role during the summer), the Siberian anticyclone (where the winter pressure is about $14 \mathrm{hPa}$ higher than the pressure in the Azores maximum and, thus, affecting strongly the pressure field in the northern Black Sea), the winter cyclonic anomaly over the Mediterranean Sea (affecting the southern part of the sea) and the summer thermic depression over North Africa. While the seasonal variability has similar appearance every year (maximum pressure values in winter and a minimum in summer), the individual years show quite different maxima (Fig. 6a). The latter gives actually the measure of inter-annual variability. The length of the analyzed period (15 years only) is insufficient to make definitive conclusions about the local climatic changes (as seen in Fig. 6a, the trend is statistically not quite obvious), but the increase of the seasonal amplitude (low in the period 1979-1982 and high in the period 1988-1991) is indicative for such changes.

The temporal variability of the wind speed (Fig. $6 \mathrm{~b})$ is characterized by the winter maximum of over $6 \mathrm{~ms}^{-1}$ and spring minimum of about $3.5 \mathrm{~ms}^{-1}$. Climatic data compiled by Staneva and Stanev (1998) give for the wind magnitudes numbers between 2 and $7 \mathrm{~m} \mathrm{~s}^{-1}$ with predominating values below $5 \mathrm{~m}$ $\mathrm{s}^{-1}$ (in more than $80 \%$ of the cases). The intensification of the atmospheric circulation in winter (when the atmospheric stratification is relatively weak) tends to enhance the air-sea heat exchange that results in pronounced cold water mass formation (Stanev et al., 1995). The seasonal variability of winds affects not only the thermal forcing, but acts as the main mechanism driving the variability in the Black Sea circulation. Inter-annual oscillations of the wind forcing are also quite important (Fig. 6b) and are well illustrated by the large winds in 1985 and end of 1993 and much weaker winds in 1991. Correspondingly, the sensible heat flux (also the total heat flux, see Sec- tion 3) correlates positively with the increasing wind speed that results in an efficient cooling.

The atmospheric temperature in the easternmost area (not shown here) is too low in the ECMWF data, this is the main drawback of the ERA data (climatological data have a maximum in this region). This is revealed by the extremely low winter temperatures along the coast (of $12-14^{\circ} \mathrm{C}$ lower than the open sea temperatures) that are perhaps associated with the insufficient horizontal resolution in the atmospheric analysis in proximity to step mountains along the coast. Approximately similar patterns are observed in the sea surface temperature, and the latter two show also quite similar course in time (Fig. 6c,d), the major difference between them being that the SST is about $2-4^{\circ} \mathrm{C}$ warmer in winter. It is also important to note that the dispersion of summer maxima in individual years from the mean ones for the period 1979-1993 is much smaller than its dispersion in winter. Thus, the inter-annual variability is mainly represented by the difference between winter temperatures in individual years.

In the climatic data, the largest basin wide humidity $(84-87 \%)$ is observed in December-January, the lowest $(60-64 \%)$ in July-August. The corresponding values calculated from the ECMWF data are $85 \%$ and $75 \%$. Obviously, the ECMWF data give larger humidity in summer than the climatic data, but more interesting is the continuous decrease of summer minima during the whole period (Fig. 6e).

\section{Discussion and conclusions}

We demonstrated in the paper that revisiting the air-sea exchange in the Black Sea based on atmospheric analysis data is quite useful since it provides promising validation estimates of climatic characteristics against the ones in available climatic data. The validation period of only 15 years is perhaps short, but the good quality of the climatology produced from the ECMWF data gives a justification that their profound analysis is worthwhile. Of particular importance is the fact that the atmospheric analysis gives correct regional estimates. This is not a trivial conclusion, which can be drawn from the existing work on the ECMWF data, showing good consistency over large regions and from the general similarity between different parts of the ocean. As a support to 
this statement, we will remind that the correlation between climatology derived from NCEP data and local climatological data was not too good in the same region for the period 1980-1986 (Staneva and Stanev, 1998). Among the positive results of the inter-comparison part of this study, we will remind that the ECMWF data give quite reasonable ranges of seasonal oscillations and net heat fluxes. We admit that the basin mean precipitation $(0.45 \mathrm{~m} /$ year $)$ is underestimated compared to climatic data $(0.57$ $\mathrm{m} /$ year), but having in mind the problems associated with modeling/measuring the precipitation and considering the different integration periods of both data sets, we find the agreement quite encouraging. This inter-comparison is actually a test of how correctly the atmospheric analysis replicates the precipitation in the area of coastal oceans. The precipitation patterns are also quite realistic, showing dilution in the eastern and southern regions and concentration of salt in the rest of the basin.

More important here is to remind about some caveats when using ECMWF data in the area of the Black Sea for different purposes. The atmospheric temperature in the easternmost area is unrealistically low and the near surface humidity in summer is larger than in the climatic data. However, the agreement with the regional climatological data is much better than in the case of NCEP data. Nevertheless, this is one of the major drawbacks in the data used here that has to be corrected in the future re-analysis, perhaps by using finer resolution in space (UKMO analysis, Stanev et al., in press).

The usage of atmospheric analysis seems to be a major step forward in establishing a climatology of the wind stress in the Black Sea. The bad data coverage over the sea that was the main problem of earlier estimates is overcome now, since atmospheric analysis is dynamically consistent. Comparisons with earlier estimates demonstrate that: (1) In the area of the northern Black Sea, where the data coverage is quite good, the atmospheric analysis gives consistent results. (2) The agreement between climatologies based on extrapolation of wind data over the southern Black Sea and the present estimates is an indirect proof that the extrapolation procedures of Staneva and Stanev (1998) were quite reliable. Thus, the basin mean wind stress magnitudes are comparable for the two data sets, as well as the horizontal patterns. Taking into account the strong dependency of Black Sea dynamics on the wind forcing (Stanev, 1990), we could anticipate that wind stress from the ECMWF analysis would give reliable forcing functions. This, along with the evidence we found here, that most of the variability is due to short periodic (synoptic) motions (this has been earlier addressed also by Golubev and Kuftarkov, 1993 and Staneva et al., 1995), makes the use of these data quite important.

Another issue addressed here was how the global re-analysis "sees" the air-sea interaction in one small and very specific region. The answer is that the northward transport of heat per unit length is two orders of magnitude smaller than in the Atlantic ocean. Thus, the very shallow response of the Black Sea thermal structure to the atmospheric forcing is well detected in the analysis data even though the dynamics of the Black Sea were not considered for the analysis. We admit that the small thermal inertia of the Black Sea is discussed earlier (Solyankin, 1962; Stanev, 1990); however, the new result here is that this small inertia is well detected in the analysis data which is a good benchmark that each consistent data set for this region has to pass. Thus, we see good perspectives in using ECMWF re-analysis data for driving coupled regional atmospheric and Black Sea models.

The local response of oscillations in the Black Sea to the global forcing is not sufficiently addressed in the Black Sea oceanography (see the papers of Polonsky, 1997 and Polonsky et al., 1997). Therefore, the analysis of climate variability in the period 1979-1993 and its dependency on NAO needs profound analysis, which is beyond the scope of this article. This is an issue that can motivate further studies on the air-sea exchange in the region and its interaction with global climate variability using coupled regional atmosphere-ocean models.

From the present analysis and discussions, it is obvious that the climatology of air/sea fluxes (i.e. heat, water and momentum fluxes) derived from the ECMWF re-analysis, which are able to resolve seasonal as well as intra- and inter-annual variability, is mainly in the range of the discrepancy between climatological flux estimates derived from different data sources (see Table 2). An exception can be found comparing the relative humidity, for which the 
ECMWF data show much higher summer values, compared to earlier estimates. This is mostly due to the dew point temperature, which is too low in the ECMWF data. However, relating this discrepancy to the observed variability and trends of the relative humidity in summer, this could be caused as well by the choice of the re-analysis period (1979-1993) and the too short data period with respect to climatological estimates, which requires at least a 30 -year period of data. Overall, it can be concluded that the ECMWF data reflect quite well the atmospheric conditions over the Black Sea, even if they are not able to resolve the regional fine structure in the Black Sea, due to the coarse resolution of about $1^{\circ}$.

\section{Acknowledgements}

We are grateful to Dorothee von Berg for the preparation of figures and the help in analysing the data, and to Julia Dellnitz for the data preparation. The study was partly financed by the University of Sofia, the Zentrum für Meeres- und Klimaforschung der Universität Hamburg and the EU in the frame of the INCO-Copernicus project: 'Ventilation of the Black Sea anoxic water', (ERBIC15CT960113).

\section{References}

Anonymous, 1998. Proceedings of the 1st WCRP International Reanalysis Conference (Silver Spring, MD, 27-31 Oct, 1997). WCRP/WMO, No. 876.

Efimov, E.V., Timofeev, A., 1990. Studies on the heat balance of the Black Sea and Azov Sea. Mar. Hydroph. Res. Inst. Press, Obninsk, 121 pp. (in Russian).

Gibson, R., Kallberg, P., Uppala, S., 1996. The ECMWF re-analysis (ERA) project. ECMWF Newsl. 73, 7-17.

Golubev, Y.N., Kuftarkov, A.Y., 1993. On the flux of momentum at the Black Sea surface. Meteorol. Gidrol. 3, 92-97 (in Russian).

Golubeva, A., 1984. Variability of the Black Sea heat balance. Tr. GOIN 180, 21-32 (in Russian).

Ivanov, L.I., 1998. Physical and chemical responses within the Black Sea pycnocline to cooling at the surface. Workshop Reports Series No. 1/05/98. Ventilation of the Black Sea anoxic waters, Liege, Belgium, 4-8 May 1998.

Korotaev, G.K., Saenko, O.A., Koblinsky, C.J., Demishev, S.G., Knysh, V.V., 1998. An accuracy, methodology, and some results of the assimilation of the TOPEX/POSEIDON altimetry data into the model of the Black Sea general circulation. Earth Res. Space 3, 3-17 (in Russian).
Leetmaa, A., Hggins, W., Anderson, D., Delecluse, P., Latif, M., 1999. Application of seasonal to interannual predictions: a northern hemisphere perspective. In: OCEANOBS99, The Ocean Observing System for Climate, Proceedings, Session $1 \mathrm{~B}, 14 \mathrm{pp}$.

Makerov, Yu.V., 1961. Heat balance of the Black Sea. Tr. GOIN, Moscow 61, 169-183 (in Russian).

Polonsky, A.B., 1997. Variability of hydrological characteristics of North Western Black Sea induced by large scale processes. Meteorol. Gidrol. 3, 59-70.

Polonsky, A., Voskresenskaya, E., Belokopytov, V., 1997. Variability of Northwestern Black Sea hydrography and river discharge as part of global ocean-atmosphere fluctuations. In: Ozsoy, E., Mikaelyan, A. (Eds.), Sensitivity to Change: Black Sea, Baltic Sea and North Sea. NATO Science Series 2, Environmental Security, 27. Kluwer Academic Publishers, Dordrecht, pp. 11-24.

Schrum, C., Backhaus, J.O., 1999. Sensitivity of atmosphere-ocean heat exchange and heat content in North Sea and Baltic Sea. A comparative assessment. Tellus 51A, 526-549.

Schrum, C., Staneva, J.V., Stanev, E.V., 2001. Black Sea surface climatological data for the period 1979-1993. A study based on the ECMWF atmospheric re-analysis. Berichte des Zentrums für Meeres- und Klimaforschung der Universität Hamburg 39, $72 \mathrm{pp}$.

Simonov, A.I., Altman, E.N. (Eds.), 1991. Hydrometeorology and Hydrochemistry of the USSR Seas. The Black Sea, vol. IV. Gidrometeoizdat, Moscow, $430 \mathrm{pp}$.

Solyankin, E.V., 1962. Water cycle in the Black Sea. Oceanologya 2, 238-250 (in Russian).

Sorkina, A.I. (Ed.), 1974. Reference Book on the Black Sea Climate. Gidrometeoizdat, Moscow, 406 pp. (in Russian).

Stanev, E.V., 1988. Numerical study on the Black Sea circulation. Mitt. Inst. Meereskd. Univ. Hamburg 28, 232 pp.

Stanev, E.V., 1990. On the mechanisms of the Black Sea circulation. Earth Sci. Rev. 28, 285-319.

Stanev, E.V., Roussenov, V.M., Rachev, N.H., Staneva, J.V., 1995. Sea response to atmospheric variability. Model study of the Black Sea. J. Mar. Syst. 13, 245-272.

Stanev, E.V., Beckers, J.M., Lancelot, C., Le Traon, P.Y., Staneva, J.V., Peneva, E.L., Gregoire, M., 1999. Coastal-open ocean exchange in the Black Sea: observations and modeling. Estuarine Coastal Shelf Sci. (in press).

Staneva, J.V., Stanev, E.V., 1998. Oceanic response to atmospheric forcing derived from different climatic data sets. Intercomparison study for the Black Sea. Oceanol. Acta 21, 393 417

Staneva, J.V., Stanev, E.V., Rachev, N.H., 1995. Heat balance estimates using atmospheric analysis data. A case study for the Black Sea. J. Geophys. Res. 100 (C9), 18581-18596.

Trenberth, K.E., Olson, J.G., 1998a. Evaluation of NMC global analysis: 1997-1987. Tech. Note, NCAR/TN-299 + STR, 82 pp., Nat. Cent. for Atmos. Res., Boulder, CO.

Trenberth, K.E., Olson, J.G., 1998b. Intercomparison of NMC and ECMWF global analysis: 1980-1986. Tech. Note, NCAR/ TN-301 + STR, 81 pp., Nat. Cent. for Atmos. Res., Boulder, CO. 